\title{
Trial of intensive compared with weekly speech therapy in preschool children
}

\author{
Jean Barratt, Peter Littlejohns, Julie Thompson
}

\begin{abstract}
Forty two preschool children referred to a speech therapy department were randomly allocated to receive intensive individual speech therapy or the more traditional once weekly approach. Boys and minority ethnic groups were referred most frequently. Speech therapy improved expression more than comprehension, as measured on Reynell scales. The mean improvements were 0.5 SDs $(95 \%$ confidence intervals (CI) 0.3 to 0.7 ) and 0.3 $(95 \% \mathrm{CI} 0.1$ to 0.5$)$ respectively. There was a greater improvement in children receiving intensive compared with weekly therapy in the expression scores $(0.8 \mathrm{SDs}(95 \% \mathrm{CI} 0.5$ to $1 \cdot 1)$ $v 0.2$ SDs $(95 \% \mathrm{CI}-0.1$ to 0.5$))$. White and non-white children had similar improvements in comprehension scores but white children had greater improvement in expression scores (1.1 SDs $v$ 0.3 SDs). This difference was seen in both therapy groups. Randomised trials are useful in the evaluation of speech therapy in children.
\end{abstract}

In order to maximise the effectiveness of services, different patterns of speech therapy for children are being developed, ${ }^{1}$ but their evaluation has been limited. The most common pattern to emerge is intensive group therapy. While an assessment of outcome of this approach has not been published, Richardson (P Richardson, unpublished report to Warrington Health Authority, 1987) and Onslow ${ }^{2}$ have suggested that this approach leads to increased attendances, increased throughput, and greater acceptability. However, it is not known whether it is the group environment or the intensive nature of the therapy that is the most important factor. In addition, speech therapists are increasingly concentrating on preschool children, because early intervention may modify the cause and impact of childhood speech and language disorders (S Roulstone, $\mathrm{P}$ Ison, unpublished report to Bristol and Western Health Authority, 1987). ${ }^{3}$

The speech therapy department in Wandsworth health district was receiving increased referrals without an increase in resources. This resulted in delays of six months for initial appointments in community clinics and some day nursery children not completing their course of therapy before entering school. A structured review of the services is being undertaken to assess the most cost effective way to provide speech therapy services to the local community. As part of this process, a first step was to compare the benefits of intensive individual speech therapy with the more traditional once weekly approach. This paper presents the results of a randomised trial assessing the efficacy of two patterns of treatment as well as their acceptability.

\section{Patients and methods \\ PATIENTS}

Children attending 15 day nurseries or special play groups, and three nursery classes attached to mainstream schools in the health district of Wandsworth (south west London) who were referred to the speech therapy department, were randomised to receive either an intensive course or a weekly session. In order to minimise bias within one establishment, the randomisation using random number tables was by place of referral rather than by person. To be eligible for the study children had to be aged between 2 and 5 years with no major physical or mental handicap. All children had to demonstrate limited communication in the nursery as reported by staff and fall into diagnostic categories of (a) developmental language delay, (b) a language delay which may have no identifiable cause, or (c) be associated with bilingualism or severe deprivation. ${ }^{4}$ Because of the possible effects of attendance at a preschool playgroup on accelerated language growth, it is local policy that children are only referred to the speech therapy department after one term in a school or three months in a day nursery. In addition, children had to be at least one standard deviation below the mean for his/her age on the Reynell development scales in comprehension, expression or both. ${ }^{5}$ Children had to attend at least $80 \%$ of the sessions to be eligible for the study.

\section{TREATMENT}

Treatment was carried out by three therapists who undertook both patterns of therapy. The weekly course was carried out by a speech therapist visiting the nursery one day a week for 40 minutes per child, over a six month period, with a possible maximum of 24 attendances per child. Intensive therapy consisted of a $\mathbf{4 0}$ minute session, four days per week for three weeks, in each three months of a six month period, giving a maximum of 24 attendances per child. All therapy programmes by the three therapists were devised for the individual child. The overall approach was that of language development through play, focusing on the areas of individual need for development of form, use, and content of language. This was followed by structured work according to the 
child's need for particular aspects of language. In addition, individual programmes addressed to associated and/or underlying problems of attention, perception, and communication.

\section{MEASUREMENTS}

Outcome of the trial was assessed by changes in the Reynell scales over a six month period. These were measured as SD from the value expected for a child of that age. To allow for minor differences in starting scores, changes over the six months were calculated by deducting the second from the first score. Differences in the means between the two groups were analysed by Student's two tailed $t$ tests. Because it was not practical to balance or randomise all the important confounding factors, these were taken into account in the final analysis.

Recruitment of large numbers of patients within the time available was not possible. It was anticipated that 20 patients would be recruited into each group which would give a $90 \%$ chance of demonstrating a difference of approximately 0.5 Reynell SDs, which is considered clinically relevant.

Questionnaires on the acceptability of the intensive therapy were designed for the study. They were completed by the officers in charge or heads of the day nurseries and nursery classes. Questions included the convenience of the new working pattern, quality of service provided, and the effects of speech therapy on children's participation in everyday events. The scales and questions were administered by an independent speech therapist who was not involved in treatment.

\section{Results}

Forty two children were recruited; two children from the weekly group and one child from the intensive group did not complete the $80 \%$ attendance required and were excluded from the analysis.

The characteristics of the children are shown in table 1. Over the six months both groups showed an improvement in comprehension

Table 1 Characteristics of children in each treatment group. Results are mean or number $(95 \%$ CI $)$

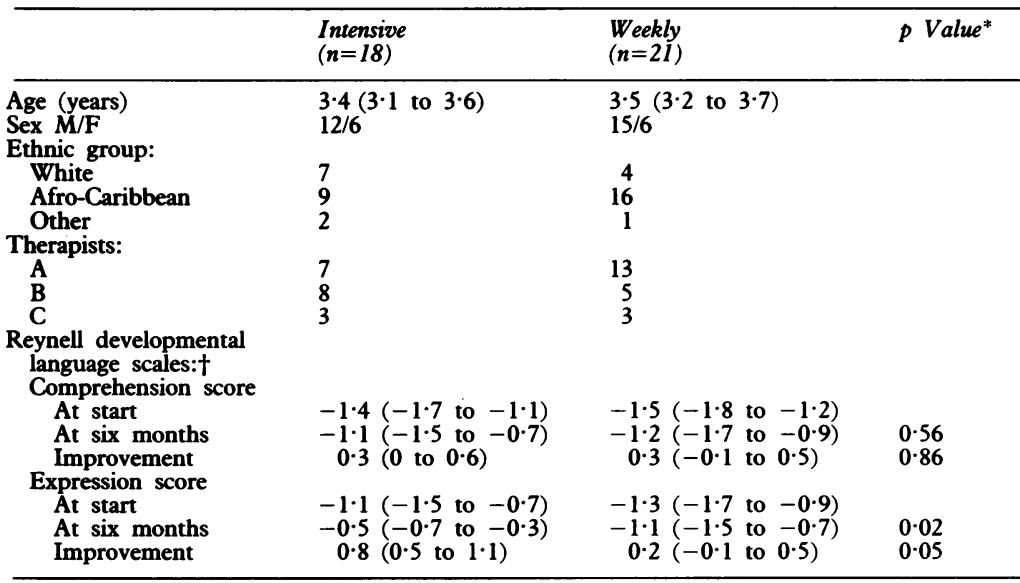

*'Student's two tailed $t$ test.

†Measured as number of SDs from the expected Reynell developmental score standardised for age. score $(p=0.07$ for intensive group, $p=0.02$ for weekly group) but the difference between the two groups was not significant. In the expression scores both groups showed an improvement $(p=<0.01$ for intensive group and $p=0.18$ for weekly groups) but the intensive therapy showed significantly greater improvement (an additional half SD).

There were no significant differences in the effectiveness of the three therapists.

Overall $69 \%$ of the children were boys. There were no significant differences between the sexes in comprehension and expression scores at the beginning of the study. There was no sex difference in the change in comprehension score (mean improvement $0.3 \mathrm{SD}$ ), but girls tended to have a greater improvement in expression scores (mean improvement $0.6 \mathrm{SD} v 0.3 \mathrm{SD}$, $\mathrm{p}=0 \cdot 2$ ).

The ethnic analysis showed $72 \%$ of children were not white. There was little difference between the comprehension scores of white and non-white children $(-1.4 \mathrm{SD},-1.5 \mathrm{SD})$ and expression scores $(-1 \cdot 6 \mathrm{SD},-1 \cdot 1 \mathrm{SD})$ at entry into the study. White and non-white children had similar improvement in comprehension scores $(0.1 \mathrm{SD}, 0.4 \mathrm{SD}, \mathrm{p}=0.28)$ but white children had greater improvement in expression scores $(1 \cdot 1 \mathrm{SD}, 0.3 \mathrm{SD}, \mathrm{p}=<0.01)$. In order to assess the independent contribution of type of speech therapy and ethnicity to the change in expression score the analysis was repeated, controlling for ethnicity. Table 2 shows that in white children the mean improvement in the intensive therapy group was 1.2 SD $(95 \%$ confidence intervals (CI) 0.8 to 1.6 ) and $0.8 \mathrm{SD}$ $(95 \% \mathrm{CI} 0.7$ to 0.9$)$ in the weekly group. In nonwhite children the mean improvement in the intensive group was $0.5 \mathrm{SD}(95 \% \mathrm{CI} 0.2$ to 0.8$)$ and in the weekly group $0.1 \mathrm{SD}(95 \% \mathrm{CI}$ -0.2 to 0.4$)$. The difference between type of therapies in white and other children was the same $(0.4 \mathrm{SD})$ which is $0.2 \mathrm{SD}$ less than the overall difference. This is due to a higher proportion of low scoring non-white children in the weekly group. When multiple regression analysis was undertaken with the change in expression score as the dependent variable and ethnic group and type of therapy as the independent variables, $35 \%$ of the variance in expression score could be explained by these two variables. The addition of sex into the equation did not significantly increase the amount of variance explained.

Of the six establishments that had received intensive therapy, three considered it to be an improvement on the weekly sessions, two did not, and one was unsure. The advantages of intensive therapy were that the child quickly built up a relationship with the therapist which was maintained; it did not need to be reestablished every week. The same was perceived

Table 2 Changes in the Reynell expression scores in the two treatment groups, controlling for ethnic origin

\begin{tabular}{llll}
\hline $\begin{array}{l}\text { Ethnic } \\
\text { origin }\end{array}$ & \multicolumn{3}{l}{ Mean change in expression score } \\
\cline { 2 - 4 } & Intensive & Weekly & Difference \\
\hline White & $+1.2(\mathrm{n}=7)$ & $+0.8(\mathrm{n}=4)$ & 0.4 \\
Other & $+0.5(\mathrm{n}=11)$ & $+0.1(\mathrm{n}=17)$ & 0.4 \\
\hline
\end{tabular}


as applicable to the staff. The disadvantages were the difficulty in fitting into the other care programmes and the lack to follow up after the period had finished. (Detailed comments are available on request.)

\section{Discussion}

There is immense variation in the rates children acquire language. ${ }^{6}$ The reasons range from normal variation to severe underlying pathology, such as hearing loss. After excluding an 'organic cause' for a child's language difficulty which is giving concern to parents, nursery teachers, or doctors, the assessment and treatment should then be by a qualified speech therapist. ${ }^{7}$ Little evaluation of the effectiveness of different types of therapy has been attempted. This study is one of the first to publish the results of speech therapy and suggests that, in an inner city district, minority ethnic groups are more likely to be referred for treatment. The findings that boys are referred more frequently than girls reflect the general patterns in the UK. Speech therapy appears to improve expression more than comprehension and intensive therapy is likely to be better than weekly therapy. Ethnic minority groups will need more help to improve their expression scores. Whether this means more of the same therapy for ethnic minorities or a different type of therapy is unclear. It may be that therapy programmes designed along the lines of language development in English give white children an advantage when assessed on the Reynell scales.

This study was designed to assess two patterns of speech therapy; it did not have a control group so we do not know what effects a preschool environment alone has on speech and language development. The delay in referral, however, should have minimised any beneficial effects of a preschool placement on the trial results. Each type of placement will have a different approach to language based activities but the randomisation should have ensured that these effects were equally distributed in both treatment groups. Randomised controlled trials of new treatment usually have a control or placebo study, but incorporating this design into an established pattern of care, where practitioners already have opinions on treatment, has proved difficult in many branches of medicine. ${ }^{8}$ Trials have been considered inappropriate for evaluating speech therapy ${ }^{9}$ but in the 'new' NHS, assessment of services will be required as therapists will be increasingly accountable for both their client selection and the efficacy of their procedures. ${ }^{10}$

Measurement of the outcome of a clinical trial where the treatment is a service are notoriously difficult. ${ }^{11}$ In this study, a numerical score was obtained for two aspects of language based on a recognised scaling system. In addition, the perception of the supervisors of these children was obtained. Scales are only a surrogate for the clinical outcome you are hoping to achieve. In order to have confidence in their application, good repeatability and validity needs to have been demonstrated. It has been accepted that the Reynell scales are useful in describing the level of language development of an individual. ${ }^{7}$ We have used the change in Reynell scale scores as an indicator of the difference in the language characteristics of a child. This assumes that the therapy did not merely train the children to perform well on the scales. Additional criticisms of this approach to assessment are twofold: first, that the improvement may be only in the context of the treatment environment and does not represent a child's capabilities in the normal environment; and secondly, that the treatment makes no change in an absolute sense to the patient but merely enables the child to reach his/her level of development more quickly. However, much rehabilitative medicine is based on this latter principle and seen as a legitimate aim, particularly in speech therapy for children under 5 years old where its aim is to bring language to the normal level for age, before school entry.

With these provisos, the next step in our review of childhood speech therapy services would appear to be randomised controlled trial of intensive individual and intensive group therapy with a control study. Further research into the differing requirements of ethnic minority groups will be part of this evaluation.

We thank Andrea Allborough for administering the questionnaire and the Reynell scales and Dr Terry Gould, general manager of the Continuing Care Unit, for supporting the study. The manuscript was typed by Mrs Loretta Hall.

1 Martin JAM, Fletcher P, Grunwell P, Hall DMP, eds. Proceedings of the first international symposium on specific speech and language disorders in children. London: Association for All Speech Impaired Children (AFASIC), 1987.

2 Onslow DJ. The efficacy of intensive group speech therapy for inner city areas. Child Language. Teaching and Therapy 1988;4:26-45.

3 Snyder-Mclean L, McLean JE. Effectiveness of early intervention for children with language and communication effectiveness of early intervention for at-risk and handicapped a: Academic, 1987:213-74.

4 Cooper J, Moodley M, Reynell J. Helping language development. London: Edward Arnold, 1978.

5 Reynell J. Reynell developmental language scales. Revised edition. Windsor: NFER Publishing Co, 1977.

6 Hall D. Delayed speech in children. BMF 1988;297:1281-2. Robinson RJ. The child who is slow to talk. $B M F 1982 ; 285$ 671-2.

8 Korn EL, Baumrind S. Randomised clinical trials with clinician-preferred treatment. Lancet 1991;337:149-52.

9 Allen CMC. Trials and tribulations in speech therapy. $B M \mathcal{F}$ 1990;301:302-3.

10 Secretaries of State for Health, Northern Ireland and Scotland. Working for patients. London: HMSO, 1989.

11 Epstein AM. The outcome movement-will it get us where we want to go? $N$ Engl f Med 1990;323:266-9. 